\title{
ABKÜRZUNGS- UND SIGELVERZEICHNIS
}

Abh. Ak. Berlin

Abh. Ak. Heidelberg

AfD.

AKG.

ALMA.

AUF.

Bibl. rer. Germ.

BOUQuet

BrH. IV.

DA.

DArn.

DH. I.

DH. II.

DH. III.

DH. IV.

DKar.

DK. II.

DK. III.

DL. III.

DLZ.

Do. I.

DO. II.

GGA.

HJb.

HV.

HZ.

Jbb.

MaNSI

MG.

Cap.

Conc.

Const.
Abhandlungen der Preußischen Akademie der Wissenschaf. ten, phil.-hist. Klasse

Abhandlungen der Heidelberger Akademie der Wissenschaften, phil.-hist. Klasse

Archiv für Diplomatik

Archiv für Kulturgeschichte

Archivum latinitatis medii aevi

Archiv für Urkundenforschung

Bibliotheca rerum Germanicarum, ed. Ph. JafFE, 6 Bde., Berlin 1864 f.

Boupuet, M., et Decisle, L., Recueil des Historiens des Gaules et de la France, Nouvelle édition, 24 Bde., Paris $1869 \mathrm{ff}$.

Brief Heinrichs IV.

Deutsches Archiv für Geschichte (Erforschung) des Mittelalters

Diplom Arnulfs von Kärnten

Diplom He:nrichs I.

Diplom Heinrichs II.

Diplom Heinrichs III.

Diplom Heinrichs IV.

Diplom der frühen Karolinger (Pippin, Karl der Große)

Diplom Konrads II.

Diplom Konrads III.

Diplom Lothars III.

Deutsche Literaturzeitung

Diplom Ottos I.

Diplom Ottos II.

Göttingische gelehrte Anzeigen

Historisches Jahrbuch

Historische Vierteljahrschrift

Historische Zeitschrift

Jahrbücher der deutschen Geschichte

Mansi, J. D., Sacrorum conciliorum nova et amplissima collectio, Florenz (später Venedig und Paris) $1759 \mathrm{ff}$.

Monumenta Germaniae historica.

Capitularia regum Francorum. 2 Bde., Hannover $1883 \mathrm{ff}$. Concilia. 2 Bde., Hannover 1893 ff.

Constitutiones et acta publica imperatorum et regum. Bd. 1-6 und 8, Hannover 1893 ff. 
DD.

DD. Karol.

DD. reg. Germ. Karol.

Epp.

Epp. sel.

Font. iur. Germ. ant.

LdL.

SS.

SS. in us. schol.

SS. rer. Germ. nova series

SS. rer. Merov.

Migne, PL.

MIÖG.

NA.

SB. Ak. Berlin

SB. Ak. Heidelberg

SB. Ak. Leipzig

SB. Ak. München

SB. Ak. Wien

St.

WaG.

ZbayrLG.

ZfG.

ZKG.

ZRG.

GA.

KA.
Diplomata regum et imperatorum Germaniae. Bd. 1-6, 8, 9, Hannover (später Weimar, Berlin und Wien/Köln/ Graz) 1879 ff.

Diplomata Karolinorum. Bd. I und 3, Hannover (später Berlin/Zürich) $1906 \mathrm{ff}$.

Diplomata regum Germaniae ex stirpe Karolinorum.

\section{Bde., Berlin 1934 ff.}

Epistolae. 8 Bde., Berlin 1887 ff.

Epistolae selectae in usum scholarum editae. Einzelausgaben.

Fontes iuris Germanici antiqui in usum scholarum separatim editi. Einzelausgaben.

Libelli de lite imperatorum et pontificum saeculis XI et XII conscripti. 3 Bde., Hannover $1891 \mathrm{ff}$.

Scriptores rerum Germanicarum. 32 Bde., Hannover $1826 \mathrm{ff}$.

Scriptores rerum Germanicarum in usum scholarum separatim editi. Einzelausgaben.

Scriptores rerum Germanicarum nova series. Einzelausgaben.

Scriptores rerum Merovingicarum. 7 Bde., Hannover $1883 \mathrm{ff}$.

Mrgne, J. P., Patrologiae cursus completus. Patrologia Latina. Paris 1844 ff.

Mitteilungen des Instituts für Österreichische Geschichtsforschung

Neues Archiv der Gesellschaft für ältere deutsche Geschichtskunde

Sitzungsberichte der Preußischen Akademie der Wissenschaften zu Berlin, phil.-hist. Klasse

Sitzungsberichte der Heidelberger Akademie der Wissenschaften, phil.-hist. Klasse

Berichte über die Verhandlungen (Sitzungsberichte) der Sächsischen Akademie der Wissenschaften zu Leipzig, phil.hist. Klasse

Sitzungsberichte der philosophisch-philologischen und der historischen Klasse der Bayerischen Akademie der Wissenschaften zu München

Osterreichische Akademie der Wissenschaften, phil.-hist.

Klasse. Sitzungsberichte

Die Reichskanzler, vornehmlich des 10., 11. und 12. Jh., von K.-F. Stumpr-Brentano, Bd. 1, Innsbruck 1865

Welt als Geschichte

Zeitschrift für bayerische Landesgeschichte

Zeitschrift für Geschichtswissenschaft

Zeitschrift für Kirchengeschichte

Zeitschrift der Savigny-Stiftung für Rechtsgeschichte

Germanistische Abteilung

Kanonistische Abteilung 